\title{
III. On analytic crystals
}

\section{H.F. Talbot Esq.}

To cite this article: H.F. Talbot Esq. (1839) III. On analytic crystals, Philosophical Magazine Series 3, 14:85, 19-21, DOI: 10.1080/14786443908649651

To link to this article: http://dx.doi.org/10.1080/14786443908649651

曲 Published online: 01 Jun 2009.

Submit your article to this journal

III Article views: 2

Q View related articles $₫$ 


\section{$\left[\begin{array}{ll}19 & ]\end{array}\right.$ \\ III. On Analytic Crystals. By H. F. TaLBot, Esq.*}

[Illustrated by Plates I. II. \& III.]

$\mathrm{T}$ the course of experiments which I made with my po1 larizing microscope, I discovered a class of crystals which produce phæenomena of great beauty, but of a nature very different from any that have been before described; for which reason a new name is necessary for them, and I have proposed that of Analytic Crystals.

I have given a brief description of them in the Philosophical 'Transactions for 1837 (page 32) †. But as I am well aware of the truth of the Horatian maxim,

"Segniùs irritant animos demissa per aures

Quàm que sunt oculis subjecta fidelibus ......"

I have here placed before the eye of the reader some coloured figures in illustration of the subject.

The usual method of displaying colours in crystalline bodies, consists in placing them between two tourmalines, called the polarizer and the analyser.

Instead of tourmalines the reflexion from plates of glass may be used; but whatever form of instrument is employed, it is necessary to have troo of them. Each of these must be capable of polarizing common light. If not, it will not serve the intended purpose. A plate of sulphate of lime, for instance, placed vertically to the eye, will not answer either as a polarizer or an analyser.

The colours displayed by crystals thus placed between two tourmalines are well known to be very complex and numerous. 'The greatest variety of tints is often seen in the field of view at once.

Now, the crystals to which my present paper refers differ from the ordinary ones chiefly in two remarkable particulars.

(1.) They display, in the arrangement which I shall afterwards déscribe, two colours only at any given time. These colours are complementary to each other, and consequently in the strongest possible contrast.

(2.) The polarizing plate is employed alone, or in conjunction with a plate of sulphate of lime. And no analysing plate is required.

From which it will readily appear how differently characterized these phænomena are from the ordinary appearances of polarized light, although equally beautiful as microscopic objects.

These results may be obtained with great facility in the following manner:

* Communicated by the Author.

[ + See Lond. and Edinb. Phil, Mag., vol, ix. p. 288 ; vol. x. p. 218.]

C. 2 
Dissolve boracic acid in boiling water, and put a drop of the solution between two plates of glass. It will immediately crystallize in irregular forms (Plate I. upper figure.).

Place it on the stage of the polarizing microscope using the polarizer only, and no analyser.

It will then be seen that these crystals (which are floating in water) present themselves under two aspects, according to the direction in rohich they lie. Those which lie one way appear with all their outlines strongly defined and extremely dark. Those which lie the other way (or vertically to the first) appear on the contrary as faint as possible. In our plate it was necessary to represent them as tolerably distinct, but in fact it often happens that their faintness is so extreme that they cease to be visible. This circumstance affords an example of one of the most curious things in optical science : for if one of the crystals has been carefully placed in this position, and a person be then desired to look into the microscope, he will confidently assert that there is no object in the field of view. If then the polarization of the light be reversed by turning the polarizer round $90^{\circ}$, the crystal will appear to start into existence, and become not only as dark as those represented in the figure, but even darker, or perhaps entirely opake.

Without entering into the theory of the matter here, it appears to me to result from this, that, of the two refractive indices of boracic acid thus prepared, one is the same with the refractive index of water.

If now, the appearance of things being as is represented in the upper figure of Plate I., we introduce a lamina of sulphate of lime below the crystals, the appearance changes to that represented in the lower figure.

If we turn the polarizer $90^{\circ}$ round, the red crystals become green, and vice vers $\hat{a}$.

It is to be observed, that the outlines only are coloured; the central parts of the crystals are generally white.

This coloration of the outlines constitutes the great beanty of some of these experiments. Its delicacy however is such as scarcely to admit of being successfully represented.

The upper figure in Plate II. represents another specimen of the same crystal, different in shape only. If now we exchange the lamina of sulphate of lime for one of different thickness, the colours change, as shown in the lower figure of the same plate.

Besides the boracic acid, I find the nitrates of potash and soda have this property in a high degree. No doubt the list may be considerably augmented; yet I think that the crystals 
which are destitute of this property are much more numerous than those which possess it.

I believe, that as a distinctive character this optical property may be of great service in chemistry. For instance, suppose that an exceedingly minute fragment of crystal (considered to be nitre) were under examination. Let it be viewed by polarized light in a manner analogous to what is above described; then if, when turned in various positions, it fails to develope two opposite colours, it follows that it cannot be a particle of nitre. I conceive that this mode of examination (when properly limited by experience) will prove a valuable auxiliary to the others already known.

Plate III. exhibits the phænomena produced by the capillary crystals of another salt-the oxalate of potash and chromium. The two figures represent the same object: the change of colour is effected by reversing the polarization of the light. It will be understood that the same change takes place by turning the olject round $90^{\circ}$. From which it will be readily seen to follow, that if a complete circle were formed of these capillary crystals (all radiating from a point) two opposite quadrants of it would appear green, and the other two red. The crystallization of this salt is remarkably elegant, but I have been obliged to confine myself in the plate to the representation of one of its simplest forms, owing to the difficulty of doing justice to those which are more complicated. I have described it elsewhere*.

Concerning the theory of these very pretty phænomena, I need say nothing in the present place, because I think that I have given a satisfactory explanation, in the Philosophical Transactions, of the cause from whence they originate.

IV. On certain Conditions under which Light is received from the Heavenly Bodies, and on the Importance of investigating them.

To the Editors of the Philosophical Magazine and Journal.

Gentlemen,

T PRESUME upon your readiness to afford every facility 1 to suggestions on scientific subjects, in sending you the few following remarks relating to a point connected with optical philosophy, which seems to deserve some consideration. Whether it really do contain anything worth further inquiry will be best ascertained by publicity among your readers.

* Phil. Trans. 1837, p. 33. [See L.\& E. Phil, Mag., vol. x. p. 219.] 
Pl.
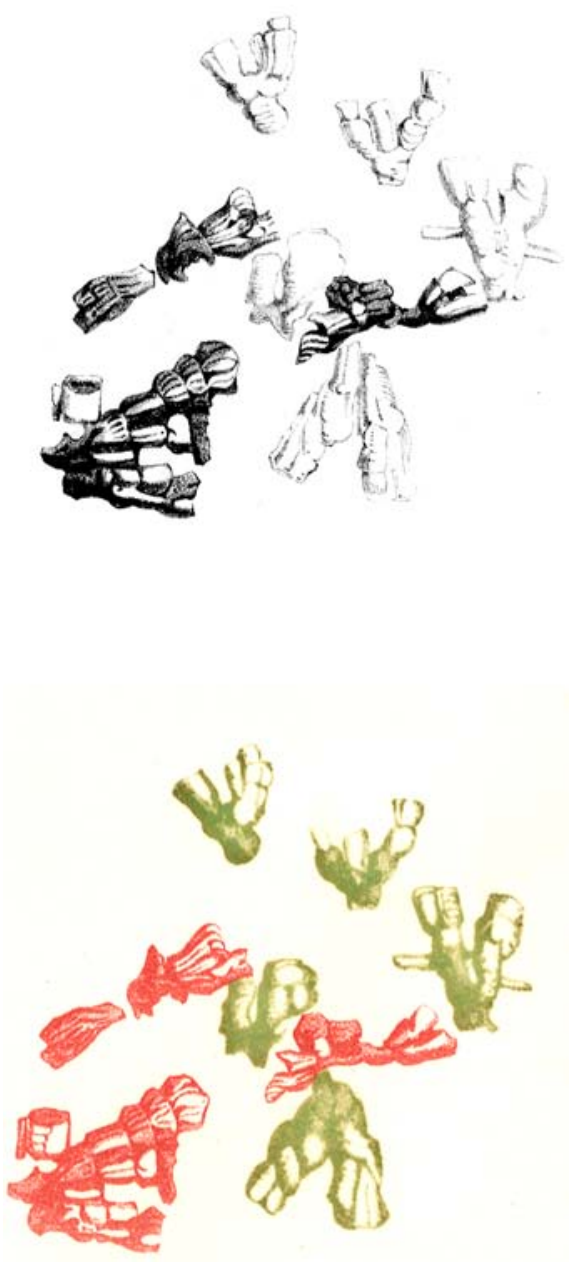

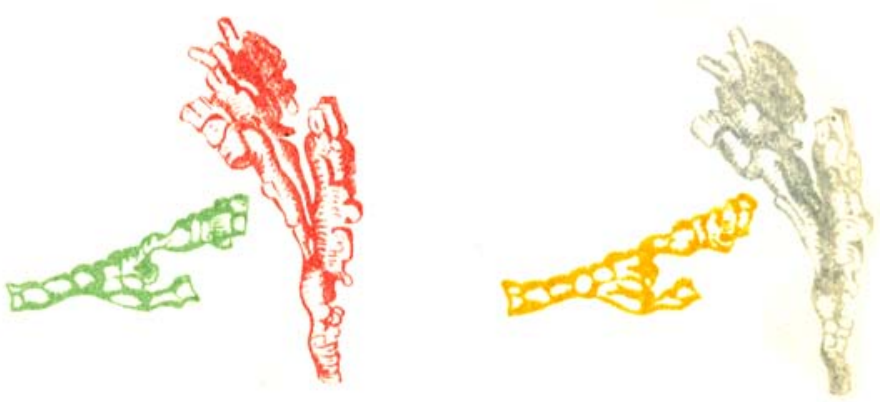

PL. 3.

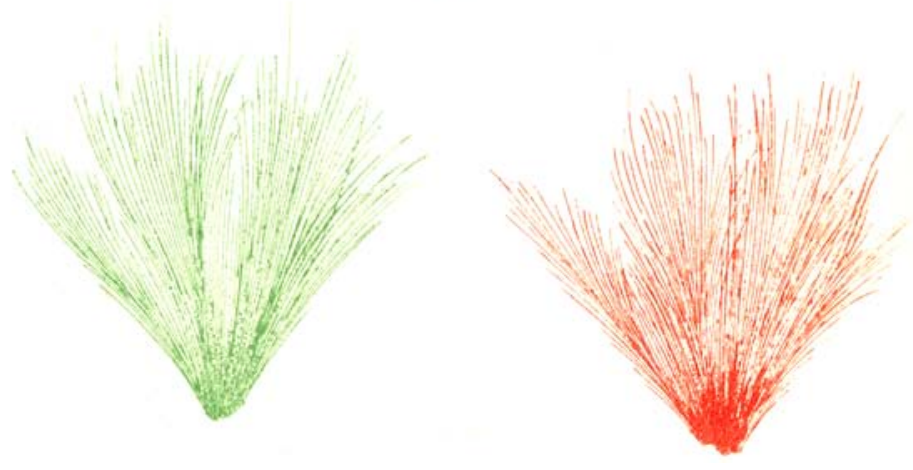

